\title{
Becoming an Antiracist Organization: Why Now for Influencing Social Policy (ISP)?
}

\author{
Marian S. Harris ${ }^{1}$
}

Published online: 3 June 2021

(c) The Author(s), under exclusive licence to Springer Nature Switzerland AG 2021

On May 25, 2020, in Minneapolis, MN, a White police officer, Derek Chauvin, brutally murdered George Floyd. Racism compels many law enforcement officers such a Derek Chauvin, to view Black/African Americans as less human than White/ European Americans; consequently, the use of lethal force is perfectly justifiable, although less lethal force was a viable option to use to subdue George Floyd. People around the world watched in living color this tragedy and readily saw that racism continues to manifest itself in America. Thus, on May 25, 2021, the anniversary of the horrific death of George Floyd, we joined his family, friends, and others around the globe to remember this Black man who died after a police officer knelt on his neck inhibiting his ability to breathe and murmured his last words "I can't breathe." These words are forever implanted in the minds of people all around the globe.

Racism and COVID-19 are two pandemics that are wreaking havoc in the lives of Black, Indigenous, and other people of color in America today. Research has demonstrated that Blacks tend to experience police brutality at much higher rates than their white counterparts, and these experiences adversely impact their health (Alang et al., 2017). "Racism in the criminal justice system kills and denies black people equal justice and equal protection under the laws guaranteed by the U.S. Constitution" (Bullard, 2021, p. 13). According to Boyd (2018), every year over 200 black individuals are killed by the police. As a result, depression and posttraumatic stress disorder (PTSD) have been found to be prevalent in communities where unarmed Blacks have been killed by the police (Bor et al., 2018).

Although racism is rampantly pervasive in the criminal justice system, it is also prevalent in other systems in this country, i.e., education, economic, health, and housing. There have been many movements that have targeted structural racism in America including the US Civil Rights Movement and the Black Lives Matter Movement. The Civil Rights Movement of the 1950s and 1960s waged an attack on varied forms of structural racism that were preponderant in the lives of Black/

Marian S. Harris

mh24@uw.edu

1 School of Social Work \& Criminal Justice, University of Washington Tacoma, 1900 Commerce Street, Tacoma, WA 98402-3100, USA 
African Americans and other people of color, i.e., voting, education, housing, employment, and transportation, as well as equal access to other public accommodations. Many people were hosed via water cannons, attacked by police dogs, beaten, and jailed; several were killed in their fight for equality. The Black Lives Matter Movement was a response to the 2012 death of Trayvon Martin, an unarmed teenager who was shot to death by a vigilante killer, George Zimmerman in Florida. Zimmerman was acquitted in 2013 which resulted in public outrage and numerous protests. "Black Lives Matter is an ideological and political intervention in a world where Black lives are systematically and intentionally targeted for demise. It is an affirmation of Black folks' contributions to this society, our humanity, and our resilience in the face of deadly oppression" (Garza, 2014). Although there has been some progress in eliminating some of the institutional, legalized racial discriminatory laws that can be traced back to the beginning of this country such as slavery, Jim Crow laws, "separate but equal" schools, and prohibitions regarding voting or owning land, racial disparities are still readily apparent when examining white lives versus Black lives in this country.

During the summer of 2020 at an ISP Board of Directors meeting, members had an open discussion about the two pandemics that are prevalent in this country today (COVID-19 and racism). This discussion also focused on the repeated shooting of Blacks by police officers across America. The ISP Board of Directors decided that the organization could not ignore what was happening in this country nor could it ignore the fact that ISP has always been a predominantly White organization. The ISP Board of Directors decided that ISP must address racism in the organization and engage in actions to become an antiracist organization. ISP joined many other national and international organizations and institutions to confront and address racism sooner rather than later. ISP started its work by making a concerted effort to diversify the board of directors and the general membership; there has been some progress in this area.

As the 2020 President Elect of ISP, I worked with Suzanne Pritzer, Gary Parker, Mimi Abramowitz, Elisa Kawam, Laura Lewis, Sunny Harris Rome, Margaret Sherraden, and Leah Hamilton to write a draft of an ISP antiracist statement that was presented to the board for their vote. The board voted, adopted, and posted the following ISP Statement to the Social Work Community on its Web site:

The devaluation and degradation of Black lives is not a recent event in our country. This persistent and systemic injustice predates the founding of this nation. However, recent events have once again brought to the forefront of our collective consciousness the painful fact that is, for too many of us, common knowledge: the repeated injustices experienced by Blacks in American are not relics of the past. They thrive in the modern day: The slaying of Almaud Arbery while jogging in Brunswick, GA; the shooting death of Breonna Taylor by police in Louisville, KY in her own apartment; the racist accusation of violence against Christian Cooper in New York City's Central Park; the desperate cry of 'I can't breathe' from the voice of Manual Ellis, Tacoma, WA who was tasered, cuffed and later died in police custody; and most recently, the tragic killing of George Floyd who when restrained by the police cried out, 'I can't breathe.' These senseless killings stem from the pervasiveness of white supremacy in law enforcement 
and racialized policing that must be disavowed and dismantled. ISP affirms all of the painful feelings experienced by Black and brown people in America. The grief, anger, and pure frustration firmly justified by our nation's deep-seated racist history. We know that all institutions by nature are steeped in privilege and have done little to recognize, validate and affirm this scourge on black and brown communities. Statements are not enough. It is incumbent upon the social work community to recognize that we all bear responsibility for this ongoing injustice, and that we are capable of proactive steps to address it, if only we have the courage and will. As part of the social work and social policy community, ISP recognizes and accepts our responsibility for this ongoing injustice and commits to take proactive steps toward change. Therefore, ISP will work with our supporters and our partner organizations to do everything within our power to dismantle the shameful and deadly systemic oppression of black and brown people (Influencing Social Policy, 2020).

The individuals discussed in the ISP statement are dead because of systemic racism resulting in continuous police violence and killing of Black men and women in America today; racism has existed since the establishment of the US Constitutional government. As part of the ongoing work required becoming an antiracist organization, ISP has been forced to address several hard questions including but not limited to the following:

- Does ISP have a goal to dismantle racism?

- Does the mission statement of ISP include antiracism?

- Is this goal reflected in the decision-making process of ISP?

- Is there a deliberate plan to develop the leadership of people of color in ISP and to share decision making power?

- What are the stated or unstated values and norms of ISP?

- Is white culture treated as the norm in ISP?

- Is advocacy on behalf of antiracism seen as part of ISP's work?

- Does ISP have a method in place to assess the satisfaction of people of color who are members of the organization?

- Is discussion of racism and oppression normal and encouraged or seen to distract from the work of ISP?

- Is ISP accountable to people of color organizations and communities who are affected by but not part of ISP?

There are no easy answers to these questions. It is always difficult to reassess an organization's mission, core values, and bylaws, yet ISP is using an antiracist lens for this reassessment. This work requires each board member to engage in a personal journey and develop some awareness of their implicit and explicit biases. "Bias is a cognitive phenomenon that denotes a preference toward a certain perspective or ideology; this preference can interfere with one's ability to be objective, impartial, or unprejudiced" (Harris, 2021, p. 141). A deep understanding of one's own implicit (unconscious) and explicit (conscious) biases is crucial to dismantle internalized racial oppression and a difficult and often painful experience for many individuals, especially those who have lived and benefitted from white privilege. 
ISP has taken to significant actions during the initial phase of its work to become an antiracist organization. One is the establishment of an Anti-Racist Action Committee. The Anti-Racist Action Committee (ARAC) will develop a set of anti-racist principles, goals, and action items, and will monitor the work undertaken by ISP's standing committees to transform ISP into an antiracist organization. The committee's goals and progress will be reported to the Board of Directors semi-annually and published on the website. The ARAC will include ISP Board members (including a member of the Executive Committee) and non-Board members. The other action is a requirement that all ISP Board members participate in Undoing Racism training that will be conducted by the Peoples Institute for Survival and Beyond, New Orleans, Louisiana, in July 2021. "The People's Institute for Survival and Beyond is a national collective of anti-racist, multicultural community organizes and educators dedicated to building an effective movement for social transformation" (The People's Institute for Survival and Beyond, 2020).

We can only end racism if we engage in the work required to address institutional policies and practices that continuously preserve and perpetuate social and economic inequality in varied systems that affect the daily lives of Black, Indigenous, and other people of color in America today. Our failure to proactively work to end systemic racism hurts every person who is victimized by this ongoing pandemic and denies all of us the opportunity to gain enormous benefits from the many contributions that Black, Indigenous, and other people have made and continue to make as productive citizens in this country. Two pandemics continue to rage in the United States and racism is the most virulent one. ISP has much work to do in the coming years but there appears to be a commitment by the board of directors and members of the organization to make a concerted effort to do the necessary work to make ISP an antiracist organization.

\section{References}

Alang, S., McAlphine, D., McCreedy, E., \& Hardeman, R. (2017). Police brutality and black health: Setting the agenda for public health scholars. American Journal of Public Health, 107, 662-665.

Bor, J., Venkataramani, A. S., Williams, D. R., \& Tsai, A. C. (2018). Police killings and their spillover effects on the mental health of black Americans: A population-based, quasi-experimental study. Lancet, 392, 302-310.

Boyd, R. W. (2018). Police violence and the built harm of structural racism. Lancet, 392, 258-259.

Bullard, R. D. (2021). From civil rights to black lives matter. In M. Mascarenhas (Ed.), Lessons in environmental justice from civil rights to Black lives matter(pp. 2-18). Sage Publications, Inc.

Garza, A. (2014, December). A herstory of the \#blacklivesmatter movement. The Feminist Wire. http:// www.thefeministwire.com/2014/10/blacklivesmatter-2/

Harris, M. S. (2021). Racial bias as an explanatory factor for racial disproportionality and disparities in child welfare. In A. J. Dettlaff (Ed.), Racial disproportionality and disparities in the child welfare system (pp. 141-158). Springer.

Influencing Social Policy. (2020). Influencing Social Policy (ISP) statement to the social work community. www.influencingsocialpolicy.org

The Peoples Institute for Survival and Beyond. (2020). The Peoples Institute for Survival and Beyond: Undoing racism workshop. www.pisab.org 
Publisher's Note Springer Nature remains neutral with regard to jurisdictional claims in published maps and institutional affiliations. 